\title{
Antileukemic Effect of Tualang Honey on Acute and Chronic Leukemia Cell Lines
}

\author{
Nik Muhd Khuzaimi Nik Man, ${ }^{1}$ Rosline Hassan, ${ }^{1}$ Cheng Yong Ang, ${ }^{1}$ Abu Dzarr Abdullah, \\ Muhammad Amiro Rasheeq Mohd Radzi, ${ }^{1}$ and Siti Amrah Sulaiman ${ }^{3}$ \\ ${ }^{1}$ Department of Hematology, School of Medical Sciences, Universiti Sains Malaysia, 16150 Kubang Kerian, Kelantan, Malaysia \\ ${ }^{2}$ Department of Medicine, School of Medical Sciences, Universiti Sains Malaysia, 16150 Kubang Kerian, Kelantan, Malaysia \\ ${ }^{3}$ Department of Pharmacology, School of Medical Sciences, Universiti Sains Malaysia, 16150 Kubang Kerian, Kelantan, Malaysia
}

Correspondence should be addressed to Rosline Hassan; roslin@usm.my

Received 27 July 2015; Revised 5 October 2015; Accepted 7 October 2015

Academic Editor: Massimo Breccia

Copyright (C) 2015 Nik Muhd Khuzaimi Nik Man et al. This is an open access article distributed under the Creative Commons Attribution License, which permits unrestricted use, distribution, and reproduction in any medium, provided the original work is properly cited.

\begin{abstract}
Complementary medicine using natural product as antitumor is on the rise. Much research has been performed on Tualang Honey and it was shown to have therapeutic potential in wound healing, and antimicrobial activity and be antiproliferative against several cancer models such as human osteosarcoma (HOS), human breast (MCF-7 and MDA-MB-231), and cervical (HeLa) cancer cell lines. To date, there was limited study on antileukemic properties of Tualang (Koompassia excelsa) Honey. The aim of this study was to evaluate the antileukemic effect of Tualang Honey on acute and chronic leukemia cell lines. Leukemia cell lines (K562 and MV4-11) and human mononuclear cell isolated from peripheral blood were grown in RPM1 1640 culture medium. The cells were incubated with increasing concentrations of Tualang Honey. After incubation, the evaluation of viability and apoptosis was performed. The morphological changes of leukemia cells were the presence of cytoplasmic blebs followed by apoptotic bodies and round shape of cells. IC IC $_{50}$ against K562 and MV4-11 was determined. Tualang Honey gave $53.9 \%$ and $50.6 \%$ apoptosis activity on K562 and MV4-11, respectively, while on human mononuclear cell it was 37.4\%. Tualang Honey has the apoptosis-inducing ability for acute and chronic myeloid leukemia (K562 and MV4-11) cell lines.
\end{abstract}

\section{Introduction}

Leukemia is malignant neoplasm of white blood cells originating from the bone marrow. It is characterized by the uncontrolled growth of blood cells. Leukemia is classified into acute and chronic leukemia. Chronic myeloid leukemia (CML) and acute myeloid leukemia (AML) develop from the progenitor of myeloid or granulocytic cells. It accounts for nearly $14.6 \%$ of all cases of leukemia in Malaysia [1]. The current mode of leukemia treatment is using chemotherapy. However, chemotherapy has its own side effects. The firstline chemotherapy used to treat CML is imatinib mesylate, a tyrosine kinase inhibitor. However it is costly and about $50 \%$ developed disease resistance later after treatment [2].

Honey has been used since ancient times for its nutritional and therapeutic value. Many types of honey are available worldwide and its constituents differ from one place to another. Tualang Honey (TH) is a local Malaysian honey, collected from wild honey bees hives on Tualang trees found in the rain forest. It has been used as a complement to treat various diseases where its therapeutic value may be related to its antioxidant properties [3]. In addition, TH also has been shown to have antibacterial, anticarcinogenic, and antiinflammatory activities.

As an antioxidant, it has several preventative effects against different diseases, such as cancer, coronary diseases, inflammatory disorders, neurological degeneration, and aging. Increase in phenolic compound in TH may contribute to its antioxidant property [4].

Previous study reported that galangin and kaempferol showed their antiproliferative effect on promyelocytic leukemia cells line (HL60) $[5,6]$. The substances such as polyphenols and phenolic acids found in honey vary according to the geographical and climatic condition; for 
example, flavanol kaempferol can be found in rosemary honey and quercetin in sunflower honey. Other study suggested that quercetin was able to induce apoptosis in leukemia K562 cell [7].

To the best of our knowledge there is limited study on the antileukemic effect of TH; thus our aim was to study its apoptosis activity on acute and chronic leukemia cell lines.

\section{Material and Methods}

2.1. Cell Culture. Both acute and chronic human leukemia cell lines (K562 and MV4-11, resp.) were purchased from ATCC, USA. These cell lines K562 originated from patient diagnosed as chronic myeloid leukemia and MV4-11 from an acute myelomonocytic leukemia patient. The base medium for this cell line was RPMI 1640, added with fetal bovine serum to a final concentration of $10 \%$, penicillinstreptomycin (pen-strep) 1\%. The cell has been cultured with air humidity, $95 \%$; carbon dioxide $\left(\mathrm{CO}_{2}\right) 5 \%$; and consistency of temperature at $37.0^{\circ} \mathrm{C}$. Cultures are maintained by the addition or replacement of fresh medium. The number of cells seeded for cultures was $1 \times 10^{5}$ viable cells $/ \mathrm{mL}$ and subcultured at $1 \times 10^{6}$ cells $/ \mathrm{mL}$. The medium was renewed every 2 to 3 days.

2.2. Isolation of Mononuclear Cells. Mononuclear cells were grown as primary cell line and function as negative control for this study. The cells were isolated by Ficoll Hypaque technique from $5 \mathrm{~mL}$ of normal donor blood. The peripheral blood was layered with the ficoll and centrifuged at room temperature $\left(15-25^{\circ} \mathrm{C}\right.$ ) for 30 minutes at $400 \times \mathrm{g}$ with brake-off (Ficoll Paque Plus Instruction Protocol 2007). The mononuclear cells in the buffy layer were collected and washed with Phosphate Buffer Saline (PBS) before incubation with TH for 24 hours at increasing concentrations. These treated mononuclear cells were stained with Monoclonal AntiHuman CD14 to ensure the purity and percentage of CD 14+ mononuclear cells. The CD14 antigen is strongly expressed on monocytes and macrophage. It is particularly of interest to use monocytes as they represent myeloid precursor.

2.3. Cytotoxicity Assay. The aim of this assay was to identify $50 \%$ Inhibitory Concentration $\left(\mathrm{IC}_{50}\right)$ of treated cell in this study. The cytotoxicity assay was performed using CytoTox 96 Non-Radioactive Cytotoxicity Assay Kit (Promega, USA). The CytoTox 96 Assay quantitatively measures lactate dehydrogenase (LDH), a stable cytosolic enzyme that is released upon cell lysis. This LDH assay was performed on K562 and MV4-11 cell lines and mononuclear cells which were treated with $\mathrm{TH}$ at increasing concentration and time at $0.1 \%, 0.2 \%$, $0.3 \%, 0.4 \%, 0.5 \%, 0.6 \%, 0.7 \%, 0.8 \%, 0.9 \%$, and $1.0 \%(\mathrm{v} / \mathrm{v})$ for 12 hours, 18 hours, 24 hours, and 48 hours. After the incubation, the supernatant was collected and then incubated in the dark place for 30 minutes. Finally the absorbent was read by using Microplate Elisa Reader.

2.4. Morphologic Studies of Cell Line. Morphologic studies using the normal inverted microscope were carried out to observe the morphologic changes of cell death in K562 cell lines elicited by TH. The stage of morphological changes via apoptosis was captured.

2.5. Assessment of Apoptosis. Based on cytotoxicity assay, $\mathrm{IC}_{50}$ was identified at 24 hours. Harvested K562 and MV411 cell lines and mononuclear cells were incubated in 95\% air humidity; carbon dioxide $\left(\mathrm{CO}_{2}\right) 5 \%$; and consistency of temperature at $37.0^{\circ} \mathrm{C}$ Then they were incubated with increased concentrations of Tualang Honey for 24 hours. After incubation, the cells were processed using Annexin V Apoptosis Detection Kit. The Apoptosis kit contained Annexin V-FITC and Propidium Iodide (PE) (BD Biosciences, San Jose, CA).

At each identified concentration of TH and at different incubation times, $1 \times 10^{5}$ cells from culture medium were isolated, washed with ice cold phosphate buffer solution, resuspended in $100 \mu \mathrm{L}$ binding buffer, and stained with $5 \mu \mathrm{L}$ of FITC-conjugated Annexin V $(10 \mathrm{mg} / \mathrm{mL})$ and $10 \mu \mathrm{L}$ of PI $(50 \mathrm{mg} / \mathrm{mL})$. The cells were incubated for 15 minutes at room temperature in the dark, followed by the additional of $400 \mu \mathrm{L}$ of binding buffer.

Finally the cells were analyzed by a FACScan flow cytometry (Becton-Dickinson, Franklin Lakes, NJ USA). For analysis, K562 and MV4-11 cell lines were gated according to their granularity and size on forward scatter versus side scatter plot. Early apoptosis and late apoptosis were evaluated on fluorescence 2 (FL2 for propidium iodide) versus fluorescence 1 (FLl for Annexin) plots. The percentage of cells stained with Annexin $\mathrm{V}$ only was evaluated as early apoptosis, while the percentage of cells stained with both Annexin $V$ and propidium iodide were evaluated as late apoptosis or necrotic stage.

2.6. Statistical Analysis. Data were obtained from at least three independent experiments. The significance of difference was evaluated using Wilcoxon signed-rank test. A probability level of $p<0.05$ was considered as statistically significant.

\section{Result}

3.1. Morphologic Changes by Light Microscopy (Figures 1 and 2). Morphologically K562 and MV4-11 cell lines were homogenous, oval mononuclear cells. After incubation and treatment with $\mathrm{TH}$, their morphological appearance showed more rounded cells' shape, membrane blebbing, formation of apoptotic body, and finally fragmentation of the cells. These changes correspond to the apoptotic activity.

3.2. Effect of Tualang Honey on Cell Viability. The impact of honey on the cell viability was analyzed by cytotoxicity assay. Exposure of the K562 and MV4-11 cells and mononuclear cells at different concentrations with time-dependent manner showed significant increase in the production of lactate dehydrogenase (Figure 3). The dose inducing $50 \%\left(\mathrm{IC}_{50}\right)$ cell growth against normal human mononuclear cells and K562 cell line were determined at $0.6 \%(18 \mu \mathrm{L})$ after 24 hours and 


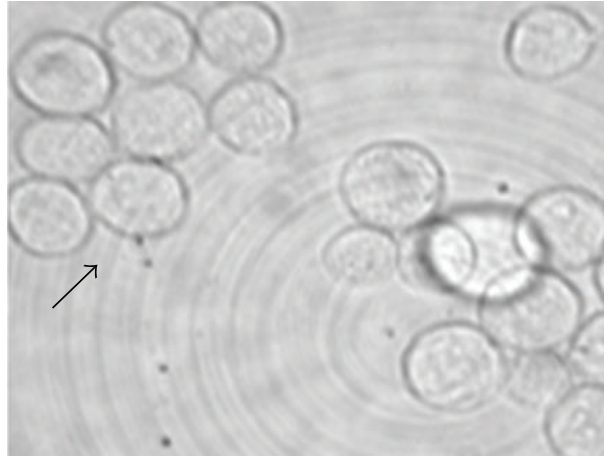

(a)

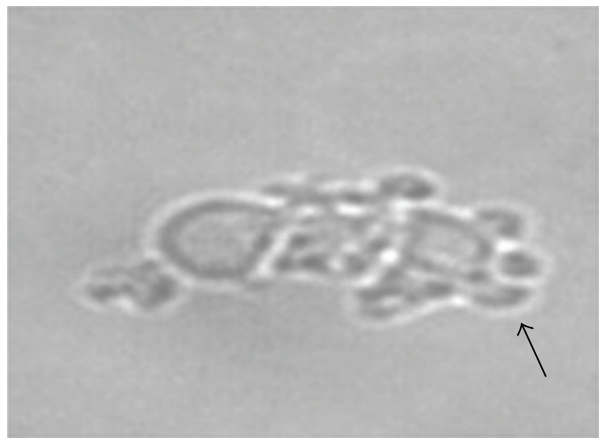

(c)

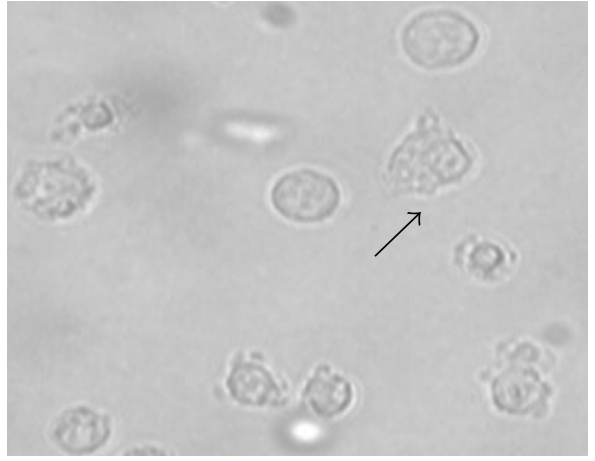

(b)

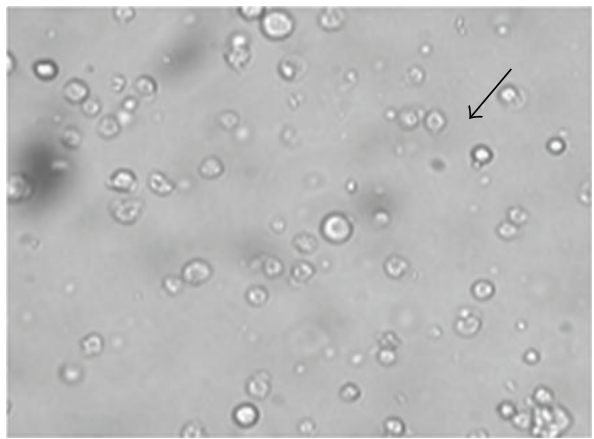

(d)

Figure 1: Photomicrograph of K562 cell line treated with $0.6 \%(18 \mu \mathrm{L})$ Tualang Honey at 24 hours. Arrow marks indicate morphology of K562 cell line and stage of apoptosis. (a) Normal morphology of K562 cell line. (b) Treated K562 cell line shows the membrane blebbing as activity of early apoptosis. (c) Formation of apoptotic body. (d) Cell lysis: the final stage of apoptosis.

MV4-11 leukemia was determined at 1.2\% (33 $\mu \mathrm{L})$ after 12 hours.

3.3. Assessment of Apoptosis Activity. TH was used to determine the apoptosis activity for two leukemic lines and a normal human peripheral blood mononuclear cell. Human peripheral blood mononuclear cell was used as a control. The percentage of apoptosis measured before and after supplement of $\mathrm{TH}$ on the normal human peripheral blood mononuclear cell was $27.7 \%$ and $37.4 \%$, respectively $(p>$ 0.05) (Figure 4). However percentage of apoptosis after treatment with $\mathrm{TH}$ at concentration of $0.6 \%$ for leukemia cell line K562 (53.9\%) was significantly higher than normal mononuclear cells $(37.49 \%)(p<0.05)$. On the other hand, there was marked reduction in the number of viable cells between untreated (86.8\%) and treated K562 (38.2\%) cell lines $(p<0.05)$ (Figure 5). Similarly for MV4-11 cell line, the apoptosis activity showed dose-dependent manner (Figure 6). At concentrations of $1.1 \%, 1.2 \%$, and $1.3 \%$ of $\mathrm{TH}$, the percentage of apoptosis was $48.3 \%, 50.6 \%$, and $51.9 \%$, respectively. Quantitative analysis using Annexin V/PI assay showed increase in both early and late apoptosis of K562 and MV4-11 cell lines after treatment with TH.

\section{Discussion}

In Southeast Asia, three types of honey bees can be found in farm, forest, and villages. The type of honey that was used in our study was TH which has been produced by the forest bees on the branches of the Tualang tree, Asia's tallest tree (growing up to 80 meters high). The Tualang tree grows in the lowland rainforests of southern Thailand, Peninsular Malaysia, Northeastern Sumatra, Borneo, and Palawan. Physicochemical properties of TH are dark brown appearance; $\mathrm{pH}$ was 3.55 and specific gravity 1.335. TH contains higher content of phenolic acids, flavonoids, and 5-(hydroxymethyl) furfural (HMF) than other local Malaysian honeys. A total of six phenolic acids (gallic, syringic, benzoic, transcinnamic, p-coumaric, and caffeic acids) and five flavonoids (catechin, kaempferol, naringenin, luteolin, and apigenin) are found in $\mathrm{TH}$ [4]. Hydrocarbons constitute more than half (58.5\%) of its composition. These include alcohols, ketones, aldehydes, furans, terpenes, flavonoids, and phenols. Some compounds found in TH previously not reported in other honeys are stearic acids, 2-cyclopentene-1,4,-dione, 2[3H]-furanone or dihydrobutyrolactone, gamma-crotonolactone or $2[5 \mathrm{H}]$-furanone, 2-hydroxy-2-cyclopenten-1-one, hyacinthine, 2,4-dihydroxy2,5-dimethyl-3[2H]-furan-3-one, and phenylethanol [8].

To date there is limited study on the effect of honey on leukemia cell lines. Most studies using honey were performed on solid cancers and showed anticancer properties. In this study, the cytotoxic and apoptotic effects of honey on K562 and MV4-11 leukemia cell line were investigated. K562 is a chronic myeloid leukemia cell line with a molecular phenotype bcr/abl gene fusion transcript while MV4-11 is 


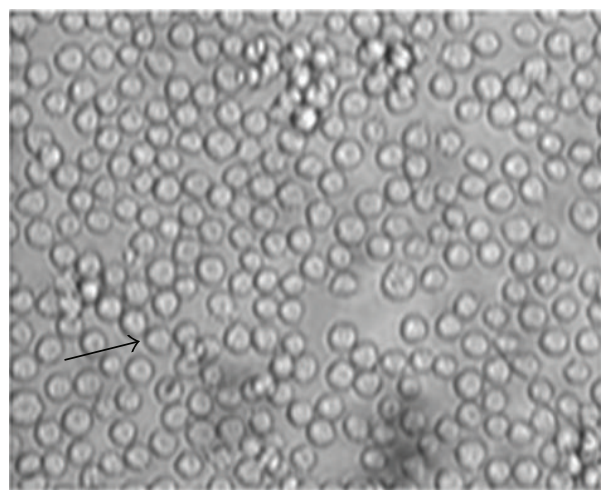

(a)

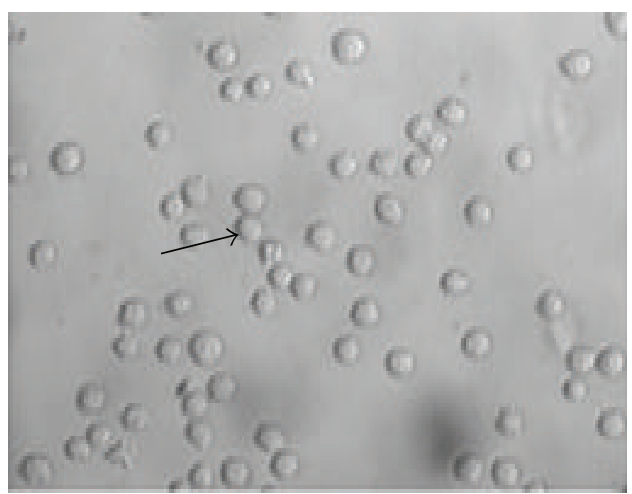

(b)

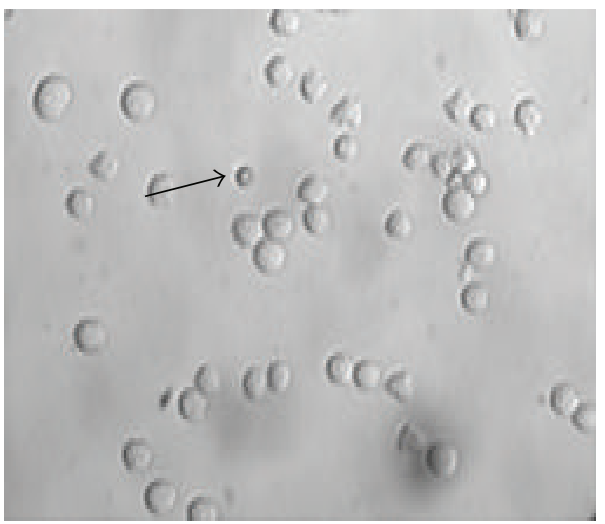

(c)

FIGURE 2: Photomicrograph of MV4-II cell line treated with 1.2\% (33 $\mu \mathrm{L})$ Tualang Honey at 12 hours. Arrow marks indicate morphology of MV4-II cell line and stage of apoptosis. (a) Normal morphology MV4-II cell line. (b) Treated MV4-II cell line shows the membrane blebbing as activity of early apoptosis. (c) Formation of apoptotic body.

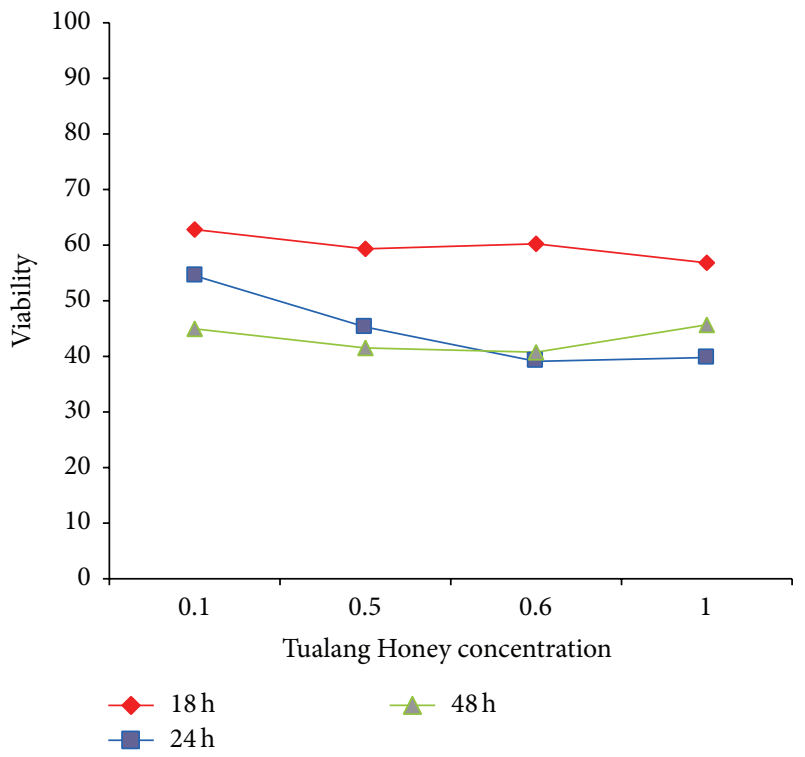

(a)

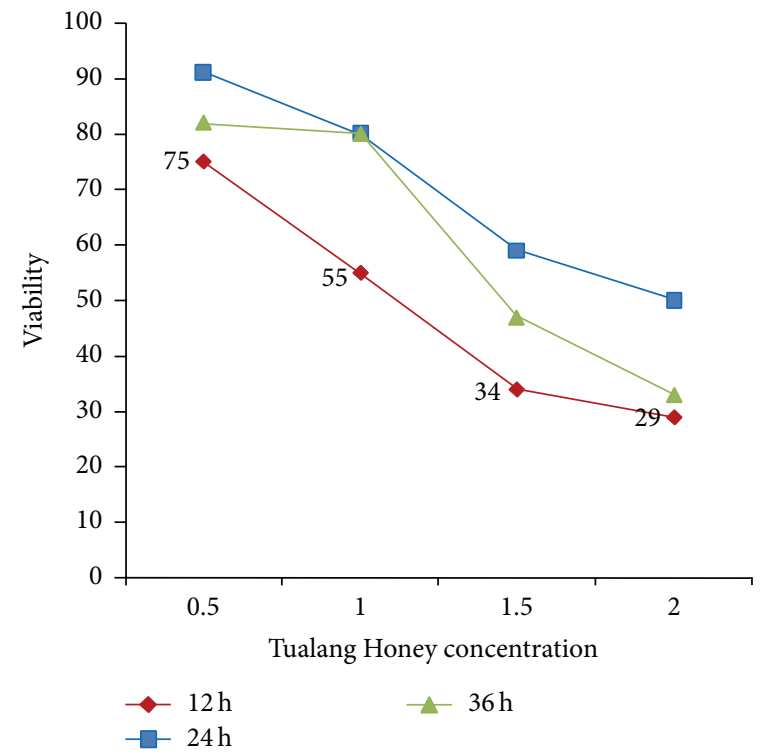

(b)

FIgURE 3: Viability of K562 and MV4-11 cell lines after treatment with Tualang Honey at various concentrations and time points. (a) IC $_{50}$ for $\mathrm{K} 562$ cell line was at $0.6 \%$ concentration of honey after 24 hours of incubation. (b) $\mathrm{IC}_{50}$ for MV4-11 cell line at 12 hours with concentration of $1.2 \%$. 


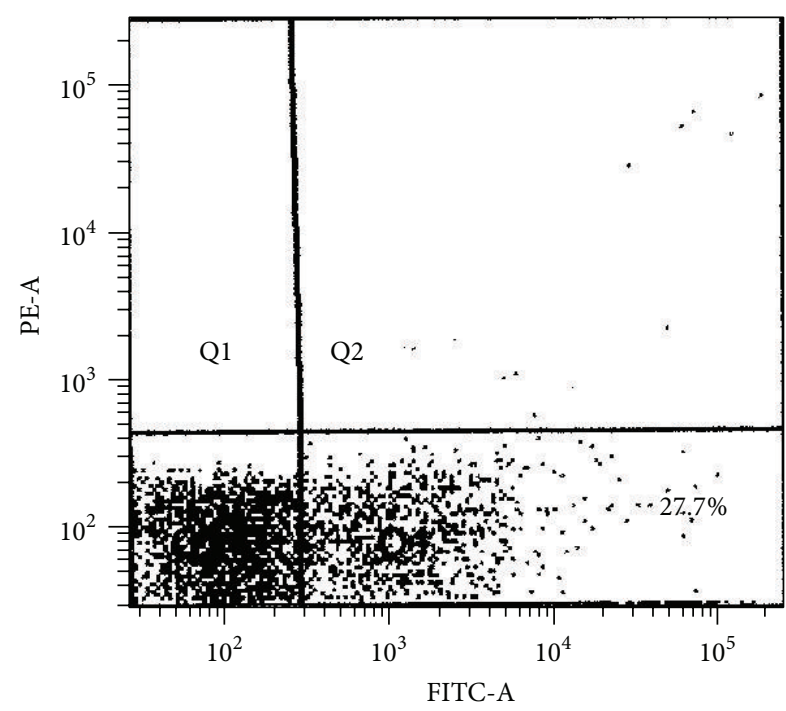

(a)

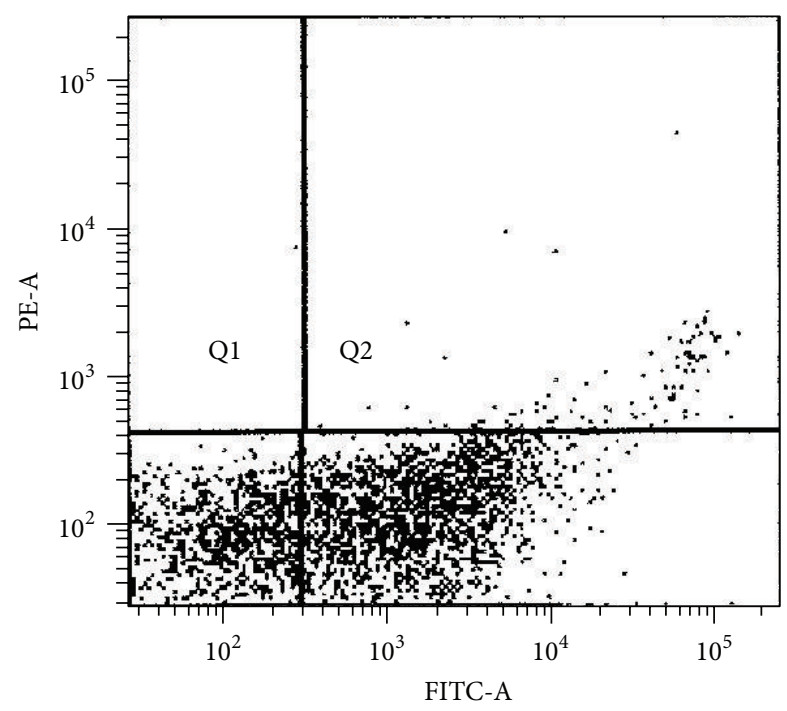

(b)

FIGURE 4: Flow cytometry analysis. (a) Untreated mononuclear cell (control) stained with Mononuclear Anti-Human CD14. (b) Treated mononuclear cell with $0.6 \%$ of Tualang Honey. Q4 is a region representing cells undergoing apoptosis while Q3 contains viable cells.

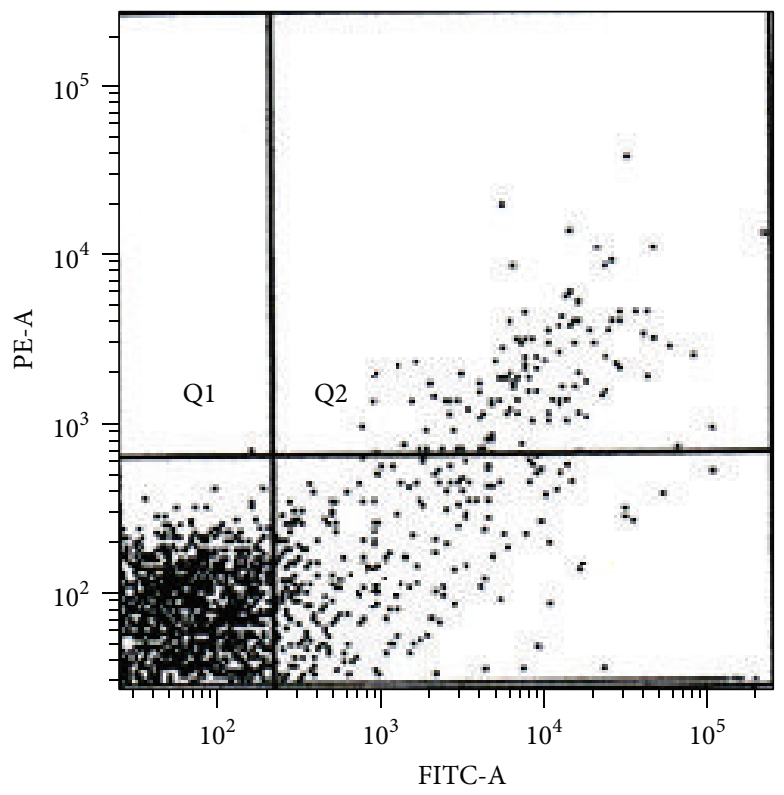

(a)

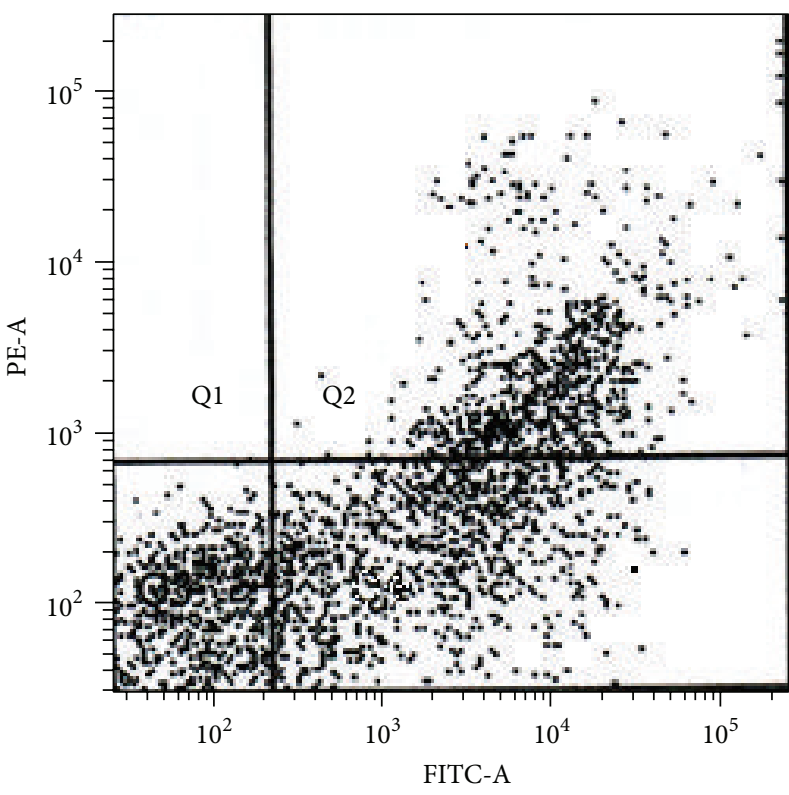

(b)

FIGURE 5: Flow cytometry analysis. (a) Untreated K562 cell line. Viable cells are 86.8\%. (b) Treated K562 cell line with $0.6 \%$ of Tualang Honey. Viable cells are $38.2 \%$. Q2 and Q4 represent cells undergoing apoptosis and stained with Propidium Iodide and Annexin while Q3 contains viable cells.

a myelomonocytic leukemia having inversion 16 karyotype. The ability to induce cell apoptosis is an important property for antileukemic effect. Cell death or apoptosis can be induced by any highly concentrated materials through the mechanism of osmosis by making the cell membrane permeable to water and causing cancer cells to swell and die. $\mathrm{TH}$ has high sugar content of $30 \%$ and produces an osmosis effect [9]. In order to provide evidence and control the condition, blood monocytes and macrophage from normal human mononuclear cells were isolated and incorporated into the study as control cells. This study has proved that TH did not significantly cause apoptosis on the normal cells as activity before and after supplement of $\mathrm{TH}$ was $27.7 \%$ and $37.4 \%$, respectively ( $p>0.05 \%)$.

On the other hand, there was a significant difference on the percentage of apoptosis between K562, MV4-11, and normal mononuclear cells with activity of $53.9 \%, 50.6 \%$, and $37.4 \%$, respectively $(p<0.05)$, using TH. It can be concluded 


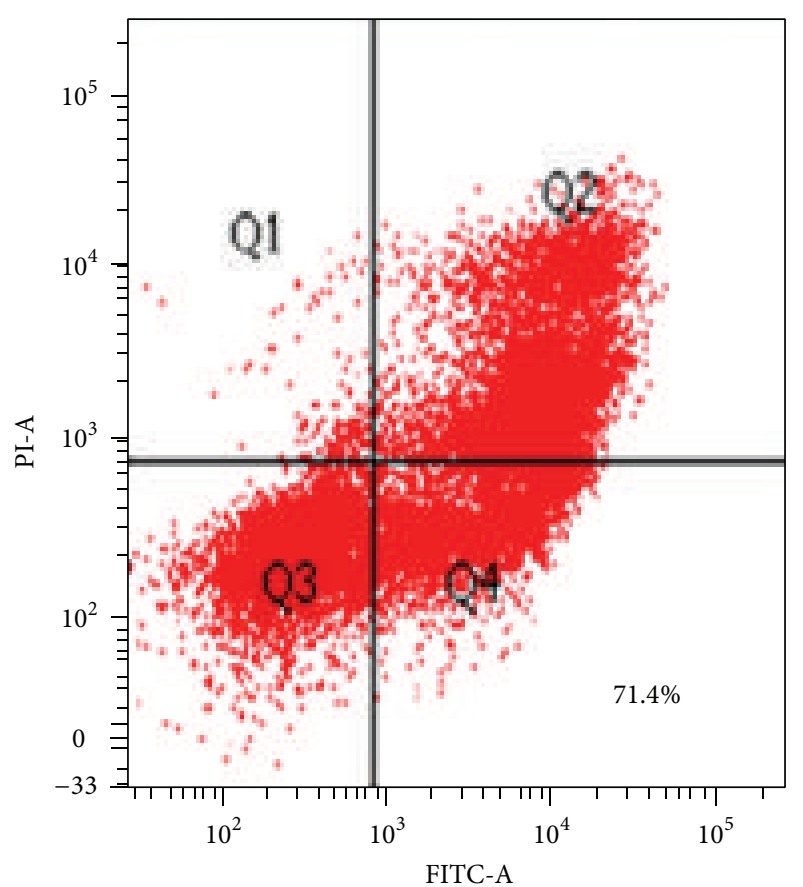

(a)

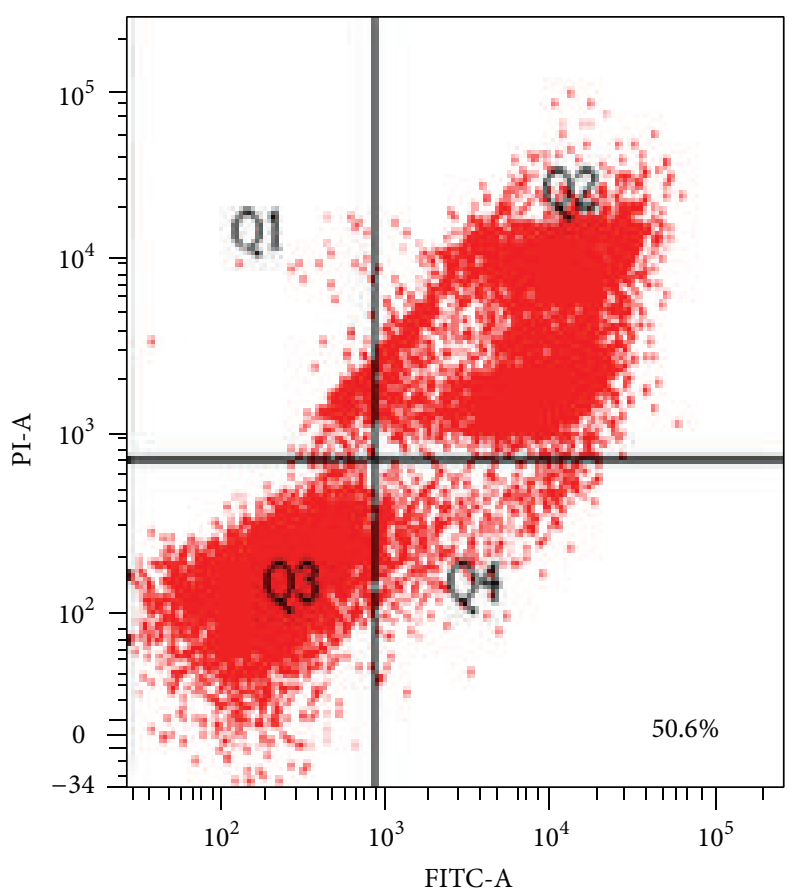

(c)

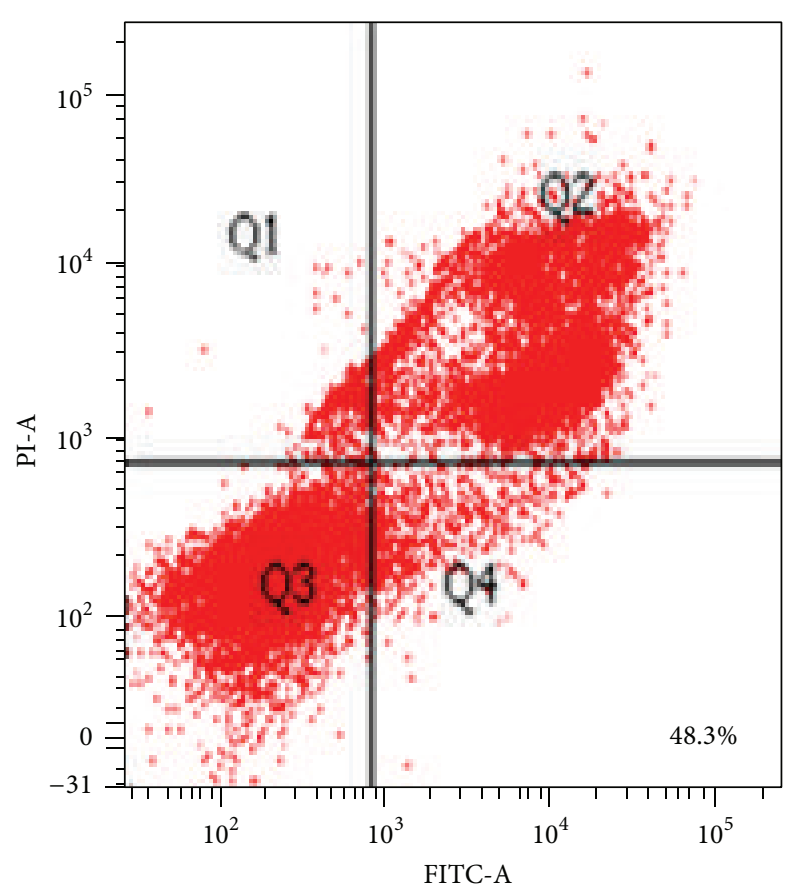

(b)

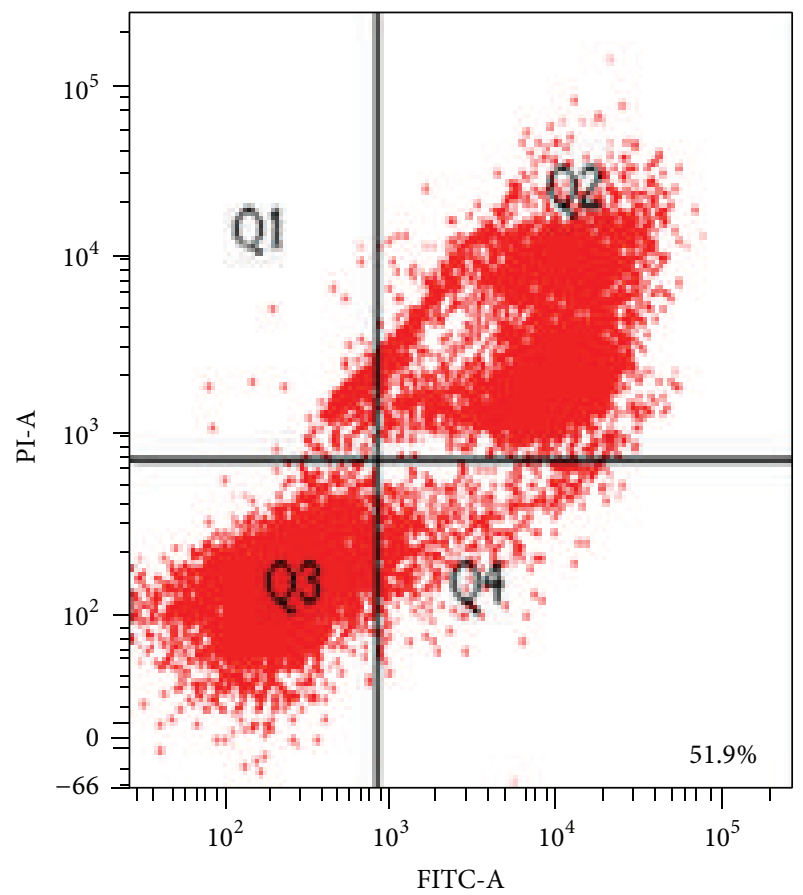

(d)

FIGURE 6: Flow cytometry analysis. (a) Treated MV4-11 cell line with camptothecin as a control. (b) Treated MV4-11 cell line with $1.1 \%$ (33 $\mu$ L) of Tualang Honey. (c) Treated MV4-11 cell line with 1.2\% (36 $\mu \mathrm{L})$ of Tualang Honey. (d) Treated MV4-11 cell line with $1.3 \%(39 \mu \mathrm{L})$ of Tualang Honey. (a), (b), (c), and (d) have been treated for $12 \mathrm{~h}$. Q2 and Q4 represent cells undergoing apoptosis and stained with Propidium Iodide and Annexin while Q3 contains viable cells and stained with Propidium Iodide and Annexin V.

that $\mathrm{TH}$ has greater potential as apoptosis induces agent for myeloid leukemia cells.

Apoptosis is characterized by distinct morphologic features, including chromatic condensation, cell and nuclear shrinkage, membrane blebbing, and oligonucleosomal DNA fragmentation. The apoptosis was confirmed by Annexin V (apoptosis detection kit) after exposure to TH. In this study the apoptosis of leukemia cell lines was prominent during 
the late stage exhibited by double positive cells by Annexin/PI in comparison to normal human mononuclear cell, where the apoptosis was at the early stage.

The apoptosis activity could be attributed by few possible compounds such as flavonoids. One of its chemical structures, namely, quercetin, has been reported to inhibit pancreatic and breast cancer cell growth and induce apoptosis via $\mathrm{Bcl}-2$ expression downregulation and upregulation of $\mathrm{Bax}$ expression $[10,11]$.

Myeloid leukemia either AML or CML is a group of malignant disorders characterized by uncontrolled proliferation of clonal hematopoietic precursor cells associated with impairment of normal hematopoiesis. Approximately 50$75 \%$ of adult patients with AML achieve complete remission when treated with cytarabine and daunorubicin or idarubicin [12]. This chemotherapy induces cell death by apoptosis mainly mediated through the intrinsic mitochondrial pathway but also through the extrinsic death receptor pathway, both of which lead to caspase activation and cell death. The mode of action by caspases either acts as initiator caspases (which include caspases 8, 2, 9, and 10) or effector caspases (caspases 3, 6, and 7). The initiator acts at the early phase of apoptotic process, while the effector acts at the late stage.

The role of apoptosis in the pathogenesis of AML has been elucidated over the past years. Some fusion proteins interact with mediators of apoptosis, sending antiapoptotic signals that favor the growth of leukemic cells: PML/RAR- $\alpha$ through the p53 pathway or AML1/ETO through the $\mathrm{Bcl} 2$ related pathway. These mediators are responsible towards chemoresistance and as such new compounds are required to induce the apoptosis of leukemic cells. The treatment strategy of any new compound aims to selectively target and kill the leukemia cells with no or limited collateral damage to normal hematopoietic progenitor cells.

Our study has shown that TH has the capacity to induce apoptosis of both myeloid leukemia cell lines with minimal effect on the normal mononuclear cells.

Interestingly $\mathrm{TH}$ induced a greater extend of apoptosis in acute myeloid leukemia (MV4-II) compared to chronic myeloid leukemia (K562). Future study is required to understand the mechanism of apoptosis underlying both types of myeloid leukemia. As natural product, $\mathrm{TH}$ has a great potential to serve as antileukemic agents.

\section{Conclusion}

This study has proved that $\mathrm{TH}$ did produce a significant apoptosis effect on both acute and chronic leukemia cell lines. Thus we conclude that $\mathrm{TH}$ could potentially serve as an antileukemic agent with the apoptosis properties.

\section{Conflict of Interests}

The authors would be happy to inform that there is no conflict of interests in producing the paper and there is no part in the paper that requires permission.

\section{Acknowledgments}

The authors would like to acknowledge the Department of Hematology and the Universiti Sains Malaysia (USM) Research Grant (no. 1001/PPSP/8120202), School of Medical Sciences, Universiti Sains Malaysia, Kelantan Health Campus for their assistance. They would also like to thank the entire staff and project members involved for their cooperation in this research project.

\section{References}

[1] G. Lim, H. Yahaya, and T. Lim, The First Report of the National Cancer Registry Cancer Incidence in Malaysia, Ministry of Health, Kuala Lumpur, Malaysia, 2003.

[2] C. M. Lucas, L. Wang, G. M. Austin et al., "A population study of imatinib in chronic myeloid leukaemia demonstrates lower efficacy than in clinical trials," Leukemia, vol. 22, no. 10, pp. 1963-1966, 2008.

[3] M. Mohamed, K. N. S. Sirajudeen, M. Swamy, N. S. Yaacob, and S. A. Sulaiman, "Studies on the antioxidant properties of Tualang honey of Malaysia," African Journal of Traditional, Complementary and Alternative Medicines, vol. 7, no. 1, pp. 5963, 2010.

[4] R. K. Kishore, A. S. Halim, M. S. N. Syazana, and K. N. S. Sirajudeen, "Tualang honey has higher phenolic content and greater radical scavenging activity compared with other honey sources," Nutrition Research, vol. 31, no. 4, pp. 322-325, 2011.

[5] C. S. Bestwick and L. Milne, "Influence of galangin on HL-60 cell proliferation and survival," Cancer Letters, vol. 243, no. 1, pp. 80-89, 2006.

[6] C. S. Bestwick, L. Milne, and S. J. Duthie, "Kaempferol induced inhibition of HL-60 cell growth results from a heterogeneous response, dominated by cell cycle alterations," ChemicoBiological Interactions, vol. 170, no. 2, pp. 76-85, 2007.

[7] Z. Akan and A. Garip, "Protective role of quercetin: antioxidants may protect cancer cells from apoptosis and enhance cell durability," WebmedCentral, vol. 2, no. 1, Article ID WMC001504, 2011.

[8] M. I. Khalil, N. Alam, M. Moniruzzaman, S. A. Sulaiman, and S. H. Gan, "Phenolic acid composition and antioxidant properties of Malaysian honeys," Journal of Food Science, vol. 76, no. 6, pp. C921-C928, 2011.

[9] S. Ahmed and N. H. Othman, "Review of the medicinal effects of tualang honey and a comparison with Manuka honey," Malaysian Journal of Medical Sciences, vol. 20, no. 3, pp. 6-13, 2013.

[10] E. Angst, J. L. Park, A. Moro et al., "The flavonoid quercetin inhibits pancreatic cancer growth in vitro and in vivo," Pancreas, vol. 42, no. 2, pp. 223-229, 2013.

[11] J. Duo, G.-G. Ying, G.-W. Wang, and L. Zhang, "Quercetin inhibits human breast cancer cell proliferation and induces apoptosis via $\mathrm{Bcl}-2$ and Bax regulation," Molecular Medicine Reports, vol. 5, no. 6, pp. 1453-1456, 2012.

[12] M. S. Tallman, D. G. Gilliland, and J. M. Rowe, "Drug therapy for acute myeloid leukemia," Blood, vol. 106, no. 4, pp. 1154-1163, 2005. 

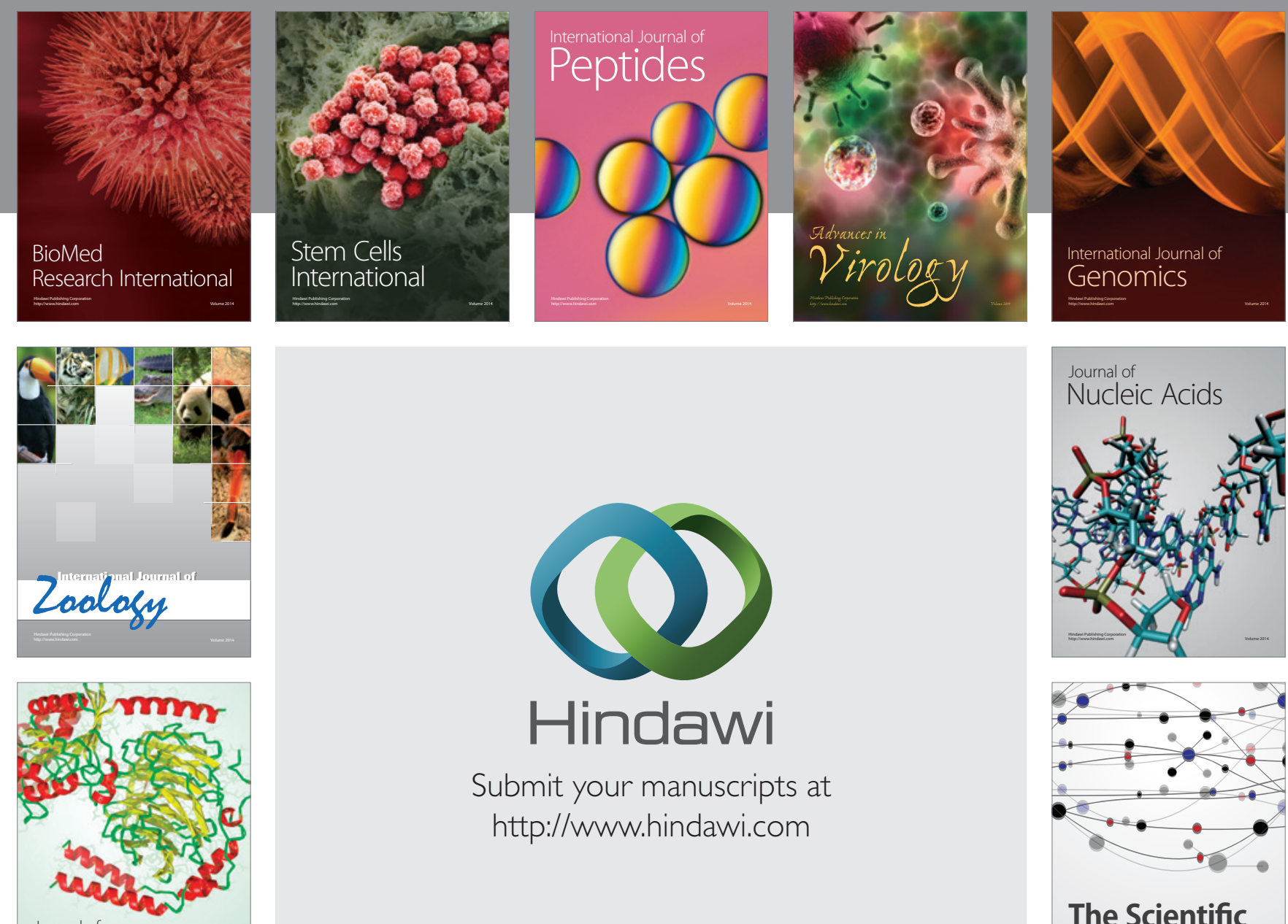

Submit your manuscripts at

http://www.hindawi.com

Journal of
Signal Transduction
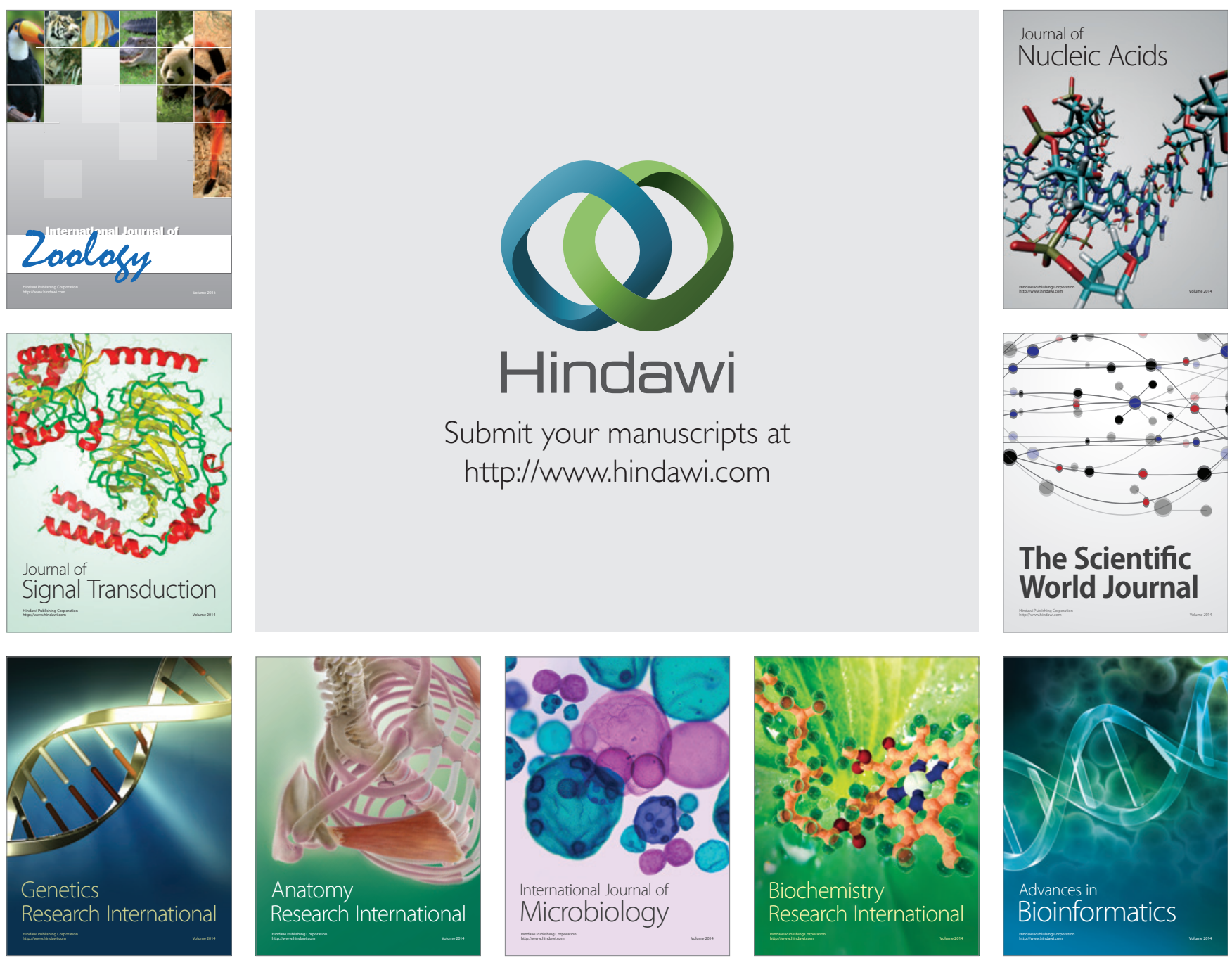

The Scientific World Journal
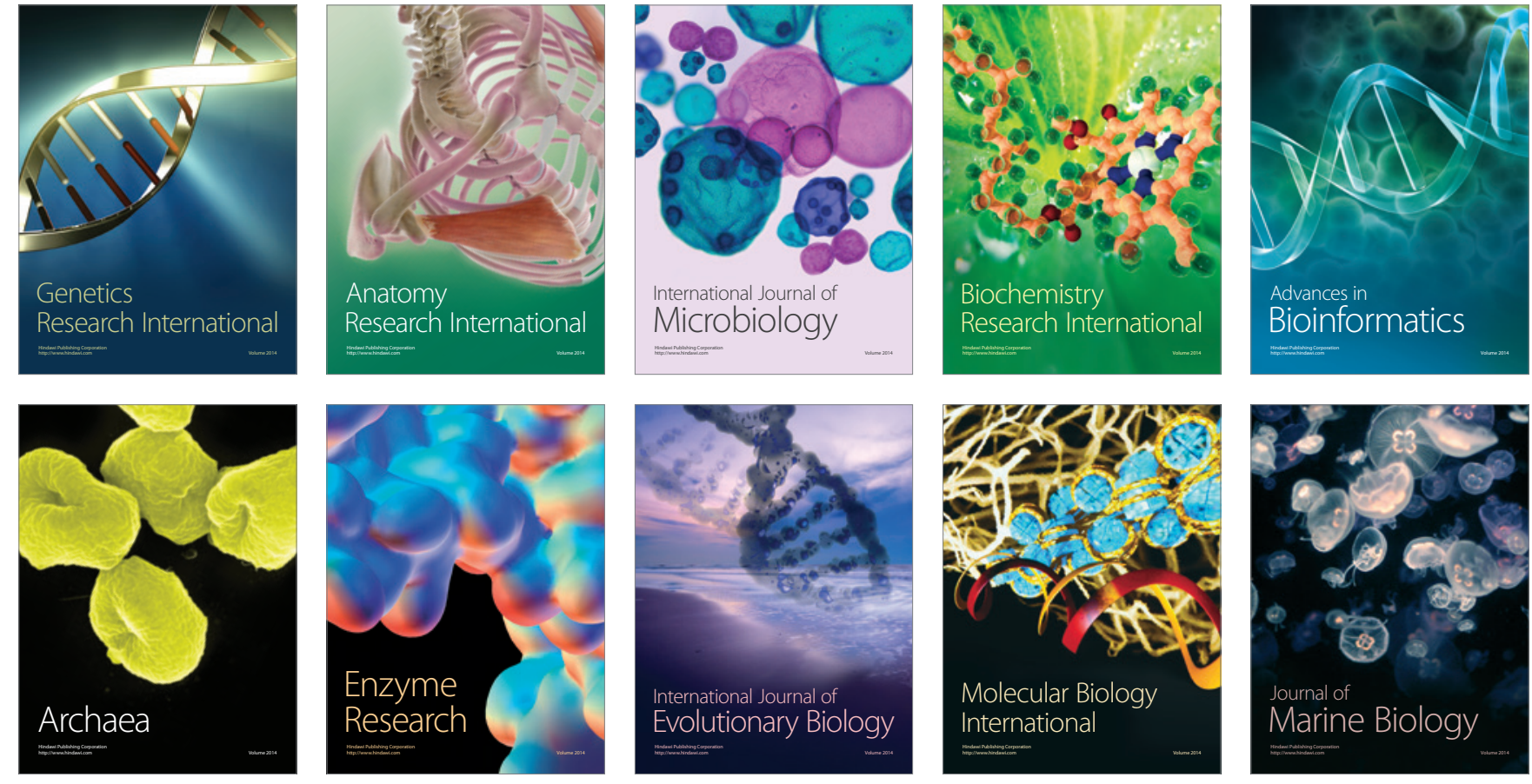